\title{
Control and simulation of a stand-alone wind-hydrogen generation system
}

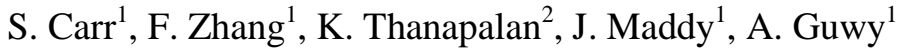 \\ ${ }^{1}$ Sustainable Environment Research Centre (SERC) \\ Renewable Hydrogen Research and Demonstration Centre \\ University of Glamorgan \\ Baglan Energy Park, Baglan \\ Port Talbot SA12 7AX, UK \\ Phone/Fax number: +0044 01639 814510, e-mail: sjwcarr@glam.ac.uk \\ ${ }^{2}$ Sustainable Environment Research Centre \\ Faculty of Advanced Technology \\ University of Glamorgan \\ Pontypridd, CF37 1DL, UK
}

\begin{abstract}
The potential to produce hydrogen from renewable resources is of considerable interest due to fears over man-made climate change and resource depletion. Hydrogen produced from renewable resources can be used to generate electricity through a fuel cell, or for other uses in a hydrogen economy. There are a number of potential system configurations for hydrogen production from electrolysis including grid connected and standalone. In remote locations, stand-alone configurations are of interest, and may prove more economically viable than grid connected systems. In this paper a standalone wind - hydrogen generation system is designed and proposed to take advantage of an electrolyser capable of operating at very low power levels. A dynamic model of the system is presented, along with a maximum power point (MPPT) control algorithm of the system. The potential yield of such a wind-hydrogen stand-alone system located at the University of Glamorgan's Hydrogen Centre is investigated using wind speed data collected at the site and the performance of the system under variable wind conditions determined.
\end{abstract}

\section{Key words}

Wind, Hydrogen, Control, Energy Storage

\section{Introduction}

Renewable energy is likely to be increasingly important to our future energy supplies. With large amounts of renewable energy entering our energy systems in the near future, the way we utilise our energy resource is of interest. Where resources are not located near to suitable electricity infrastructure, the energy generated from the renewable resource must be used in some other way, or converted to a stored form of energy. In this case, a standalone system must be designed and built. Standalone systems may incorporate some form of energy storage in order that the generated energy can be used at a time convenient to the application. Storage types such as battery storage and hydrogen storage can be considered.

A number of previous studies of stand-alone wind power systems have been reported. These include systems operating with battery storage [1-3]. Studies considering hydrogen generation have focused on the supervisory control of the system [4], or the control in conjunction with a battery system [5]. A number of different windhydrogen systems have been proposed. These include those using hydrogen as a storage mechanism for a standalone system and incorporating an electrolyser, hydrogen storage and a fuel cell [6], with short term storage such as batteries also included [5, 7, 8]. Standalone systems using other renewable sources such as PV have also been considered [2]. Other papers have considered systems dedicated solely to renewablehydrogen production $[4,9,10]$. A standalone renewable hydrogen production system can be configured in a number of ways. A DC bus bar may be used with the DC voltage imposed by a battery. In this case, as well as the controllable AC/DC conversion system connecting the wind turbine to the DC bus bar, another DC/DC converter must be incorporated to connect the electrolyser to the DC bus bar. It is of interest to keep the system as simple as possible, to help reduce costs, increase efficiency, and improve reliability in stand-alone scenarios. This can be achieved by removing the DC bus bar, and connecting the electrolyser directly to the wind turbine with a controllable AC/DC converter.

This system configuration was investigated by Battista et al [10], who investigated the control of such a system to ensure the electrolyser operated within set parameters defined by the minimum and maximum electrolyser power and ramping rates. Below the minimum electrolyser power, an auxiliary power supply was 
connected to the system. Electrolysers with no minimum power constraint, that are able to operate at very low current levels (i.e. down to zero power) are desirable, and possible in standalone systems in order to maximise the amount of energy captured from the wind and converted to Hydrogen, and to simplify the operation of the system. However, the electrolyser cannot pass current before a certain minimum voltage is applied across it, affecting the operation of the system on start up. This can be solved by connecting a capacitor in parallel to the electrolyser, in order to allow current to flow in the system at start up.

In this paper, a standalone wind-hydrogen storage system with no auxiliary power supply is dynamically modelled and simulated using MATLAB/Simulink ${ }^{\mathrm{TM}}$ and a maximum power point tracker implemented, in order to assess the performance of the system. The electrolyser considered is capable of operating over the full range of input powers. A $12 \mathrm{~kW}$ Proton Exchange Membrane (PEM) electrolyser located at the Baglan Hydrogen Centre is used as the basis to model the system in order to determine the performance of the wind-hydrogen system. The variation in load which the electrolyser sees, is determined. The wind turbine is assumed to be connected to a Permanent Magnet Synchronous Generator (PMSG) wind turbine. In addition, the potential yield from a windhydrogen plant located at the University of Glamorgan's Hydrogen Centre located at Baglan in South Wales is determined using historic wind data from the site.

\section{Wind-Hydrogen System Modelling}

The Wind-Hydrogen generation system is shown in Figure 1. It consists of a $12 \mathrm{~kW}$ wind turbine, Permanent magnet synchronous generator, three phase full bridge diode rectifier, DC/DC buck converter and a PEM electrolyser.

\section{A. Wind Turbine Model}

The output power of a wind turbine can be calculated using the well known equation.

$$
P_{m}=C_{p}(\lambda, \beta) \frac{\rho A v^{3}}{2}
$$

where, $P_{m}$ is the mechanical output of the turbine, $C_{p}$ is the power coefficient of the turbine, $\rho$ is the air density, $A$ is the swept area of the turbine, $v$ is the wind speed, $\lambda$ is the tip speed ratio and $\beta$ is the blade pitch angle. The wind turbine has a cut in speed of $3 \mathrm{~m} / \mathrm{s}$ and produces its maximum power at $12 \mathrm{~m} / \mathrm{s}$. At wind speeds above $12 \mathrm{~m} / \mathrm{s}$ the power output of the turbine remains constant.

$C_{p}(\lambda, \beta)$ can be modelled as a generic equation based on the turbine characteristics

$$
C_{p}(\lambda, \beta)=C_{1}\left(\frac{C_{2}}{\lambda_{1}}-C_{3} \beta-C_{4}\right) e^{-\frac{C_{5}}{\lambda_{1}}}+C_{6} \lambda
$$

Where

$$
\frac{1}{\lambda_{1}}=\frac{1}{\lambda+0.08 \beta}-\frac{0.035}{\beta^{3}+1}
$$

Where the parameters $C_{1}$ to $C_{6}$ define the shape of the $C_{p}$ curve. The tip speed ratio $\lambda$ is given by

$$
\lambda=\frac{r w_{m}}{v}
$$

Where $r$ is the turbine blade length (m) and $w_{m}$ is the angular shaft speed ( $\mathrm{rad} / \mathrm{s})$. The pitch angle $\beta$ is used to control the speed of the wind turbine above rated wind speeds. $C_{p}^{\max }$ occurs for a given value of tip speed ratio. The goal of controlling variable speed wind generation is to ensure the tip speed ratio is at its optimum value as the wind speed varies.

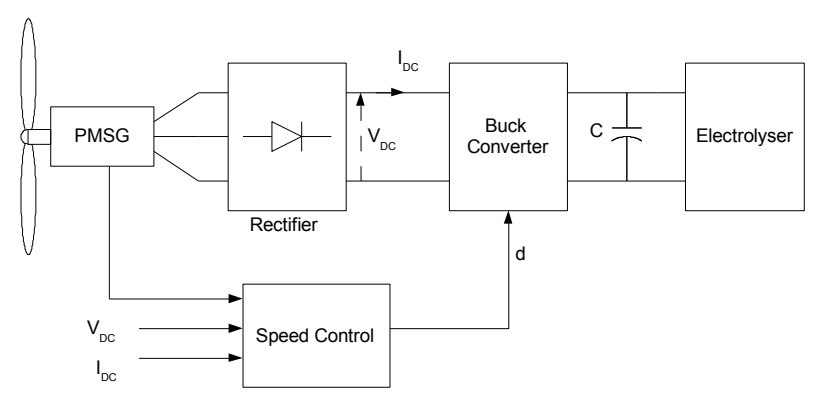

Fig. 1. General diagram of the wind-hydrogen generation system, with variable speed PMSG generator.

\section{B. PMSG Model}

Due to the size and stand-alone nature of the system, a permanent magnet synchronous generator is used to convert the power from the wind turbine into electrical. PMSG is a good option for stand-alone systems due to their self-excitation and high efficiency $[11,12]$. The PMSG allows the wind turbine to operate at variable speeds to maximize the power extracted from the wind. The PMSG is modelled in its rotating dq reference frame. The equations governing the PMSG are given by

$$
\begin{gathered}
\frac{d}{d t} i_{d}=\frac{1}{L_{d}}\left(v_{d}-R_{s} i_{d}+L_{q} w_{e} i_{q}\right) \\
\frac{d}{d t} i_{q}=\frac{1}{L_{q}}\left(v_{q}-R_{s} i_{q}-L_{d} w_{e} i_{d}-\psi w_{e}\right)
\end{gathered}
$$




$$
T_{e}=1.5 p\left(\lambda i_{q}+\left(L_{d}-L_{q}\right) i_{q} i_{d}\right)
$$

Where $i_{d}, i_{q}, v_{d}$ and $v_{q}$ are the $\mathrm{d}$ and $\mathrm{q}$ axis currents and voltages respectively, $L_{d}$ and $L_{q}$ are the $\mathrm{d}$ and $\mathrm{q}$ axis stator inductances, $w_{e}=p w_{m}$ is the electrical rotational speed, $\psi$ is the flux linkage, and $p$ is the number of PMSG pole pairs.

The shaft connecting the wind turbine to the PMSG is modelled as;

$$
\frac{d}{d t} w_{m}=\frac{1}{J}\left(T_{e}-T_{m}-B w_{m}\right)
$$

Where $J$ is the inertia of the PMSG and $B$ is the shaft friction co-efficient. $T_{m}=\frac{P_{m}}{w_{m}}$ is the mechanical torque.

\section{Rectifier and DC/DC converter}

The three phase AC power from the PMSG is rectified to DC power and then filtered and connected to the electrolyser via a DC/DC buck converter. The duty cycle of the buck converter is controlled so that the DC bus voltage is such that the wind turbine rotational speed follows the maximum power point. The rectifier is modelled as a full bridge diode rectifier, whilst the buck converter is modelled as an ideal converter, with the ratio between the input and output voltage defined by the duty cycle $d$. The current output by the rectifier and DC/DC converter is given by equation [13];

$$
i_{0}=\frac{\pi \sqrt{i_{q}^{2}+i_{d}^{2}}}{2 d \sqrt{3}}
$$

The electrolyser is modelled using its current - voltage curve. This curve represents a $12 \mathrm{~kW}$ PEM electrolyser. As mentioned above, the electrolyser is able to operate over the full range of its IV curve.

The electrolyser current voltage curve is represented by;

$$
V_{\text {elec }}=V_{r}+A i_{\text {elec }}+B \lg \left(1+C i_{\text {elec }}\right)
$$

Where $A, B$ and $C$ are parameters which define the curve. This means that no current can pass through the electrolyser below a certain voltage $\left(V_{r}\right)$ being applied across it. This causes a problem at start up of the electrolyser as if no current can pass through the circuit, The PMSG cannot begin to generate. In the full system, the rectifier will have a filter capacitor, as will the buck converter, which would allow some current to flow, however they are not designed for this purpose. To overcome this, a capacitor is placed in parallel to the electrolyser to allow current to flow and voltage to build up in start up mode, and to provide additional filtering of the electrolyser current in production mode.

In this case, on start up, the load voltage, $V_{\text {Load }}$ is given by the voltage induced across the capacitor.

$$
V_{\text {Load }}=\frac{1}{C} \int i_{0} d t
$$

Where $C$ is the capacitance of the capacitor. Once the load voltage reaches $V_{r}$, current will flow through the electrolyser as well. This current, $i_{\text {elec }}$ is given by

$$
i_{\text {elec }}=i_{0}-C \frac{d}{d t} V_{\text {load }}
$$

The load voltage is then equal to $V_{\text {elec }}$ defined by equation (10). In steady state, the electrolyser current is equal to the load current. The hydrogen production rate is calculated from the electrolyser current using Faradays law.

As the PMSG is connected to the DC load through a diode bridge rectifier, the load presents as a purely active load to the PMSG [13]. In this case $v_{d}$ and $v_{q}$ can be calculated by;

$$
\begin{aligned}
& v_{d}=\frac{V_{s} i_{d}}{\sqrt{i_{q}^{2}+i_{d}^{2}}} \\
& v_{q}=\frac{V_{s} i_{q}}{\sqrt{i_{q}^{2}+i_{d}^{2}}}
\end{aligned}
$$

Where $V_{s}$ is the stator voltage given by

$$
V_{s}=\frac{\pi V_{\text {load }}}{3 d \sqrt{3}}
$$

\section{Maximum Power Point Extraction}

The wind turbine will extract the maximum power from the wind only at a certain tip speed ratio $\lambda^{\text {opt }}$. Below rated wind speed, this value of $\lambda^{\text {opt }}$ defines the optimum coefficient of power of the system $C_{p}^{o p t}$. This means that as the wind speed varies, the rotational speed of the wind turbine must vary to find the maximum power point. The PMSG connected wind turbine is a variable speed wind turbine, and the rotational speed is directly related to the voltage at the generator terminals. The rotational speed of the wind turbine is measured and used to derive a reference power output from a turbine operating with an optimum tip speed ratio at this rotational speed. 


$$
P_{m}^{*}=K_{o p t} w_{g}^{3}
$$

Where

$$
K_{o p t}=0.5 \rho A C_{p}^{o p t} \frac{r}{\lambda_{o p t}}
$$

where $r$ is the radius of the wind turbine. This will only reach a maximum for a given rotational speed. The rotational speed of the PMSG is directly related to the DC voltage. The reference power output is used to generate a reference DC current by dividing it by the DC voltage. The duty cycle of the DC/DC converter is controlled using a PI controller to follow the reference current and ensure that the PMSG follows the maximum power point [14].

\section{E. Baglan Wind Energy Resource}

The average recorded wind speed at the Baglan hydrogen centre was recorded as $3.48 \mathrm{~m} / \mathrm{s}$ for the year 2010 . The wind speed data is available in 5 minute time steps at $1 \mathrm{~m} / \mathrm{s}$ resolution. The recorded wind speed for the month of November is shown in Figure 5. Whilst the average wind speed at Baglan is relatively low, it can be seen from Figure 2 that there are extended periods when the wind is at sufficient speed to drive the turbine and so produce Hydrogen.

The average wind speed varies between months as shown in Table 1, with the highest found to be $4.64 \mathrm{~m} / \mathrm{s}$ in July, and the lowest $1.83 \mathrm{~m} / \mathrm{s}$ in December.

\section{F. Annual hydrogen production}

The expected hydrogen production at a given wind speed in the steady state is worked out using the model presented in Section A, This hydrogen production rate is then used to calculate the expected average daily and total annual yield from a stand-alone wind hydrogen system located at the Baglan Hydogen Centre.

\section{Results}

\section{A) Dynamic modelling results}

The wind turbine power output compared to maximum power point is shown in Figure 2 after a step changes in the wind speed. The DC power produced is also shown. The results demonstrate that the MPPT works with the turbine output achieving the maximum power point in steady state. The DC power output is lower than the maximum power point due to losses in the system.

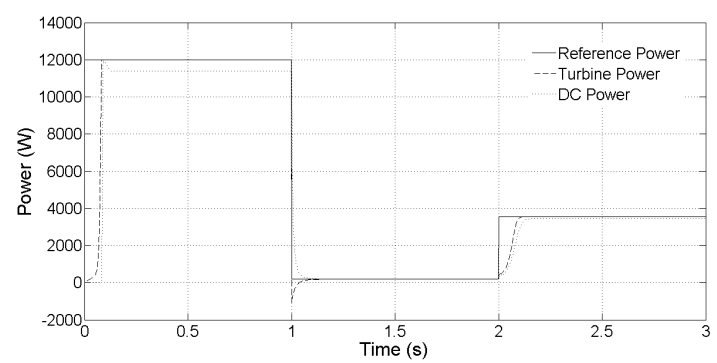

Fig. 2. Wind turbine MPPT performance - reference maximum power production, simulated power production and DC power after a step change in wind speed from $12 \mathrm{~m} / \mathrm{s}$ to $3 \mathrm{~m} / \mathrm{s}$ to $8 \mathrm{~m} / \mathrm{s}$

Figure 3 shows the voltage response of the system to step changes in wind output. It can be seen how the DC voltage alters in response to wind speed changes to maintain the maximum power point. Figure 4 shows the current response and hydrogen production. It can be seen that the capacitor draws current on start up until sufficient voltage is achieved for the electrolyser to draw current, and when the load voltage changes.

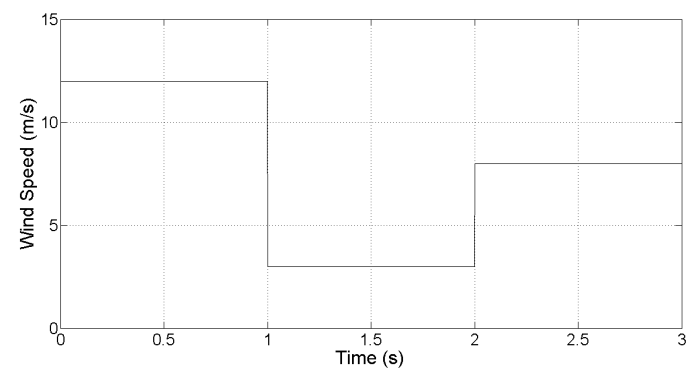

a)

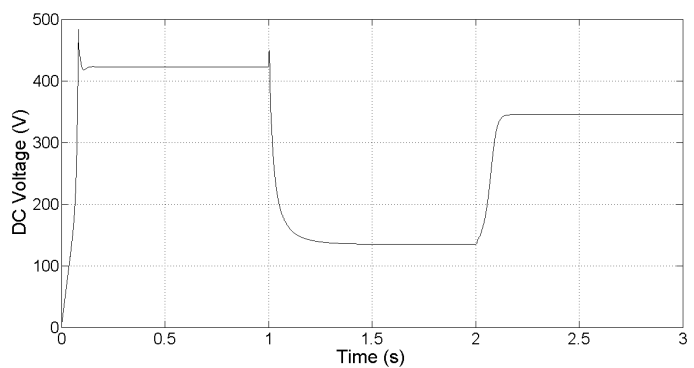

b)

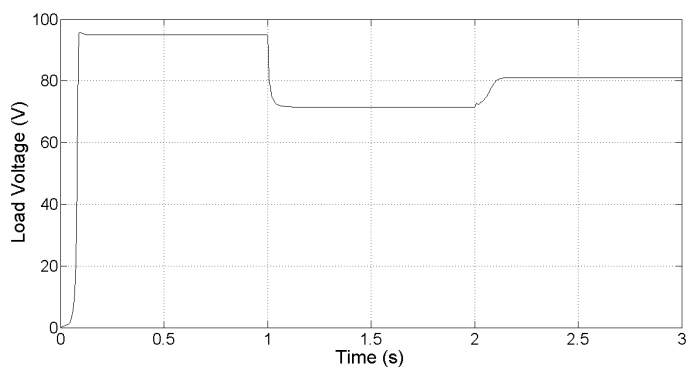

c)

Fig. 3. Change in system parameters with wind speed steps from $12 \mathrm{~m} / \mathrm{s}$ to $3 \mathrm{~m} / \mathrm{s}$ to $8 \mathrm{~m} / \mathrm{s}$. a) wind speed, b) DC voltage, c) Load voltage 


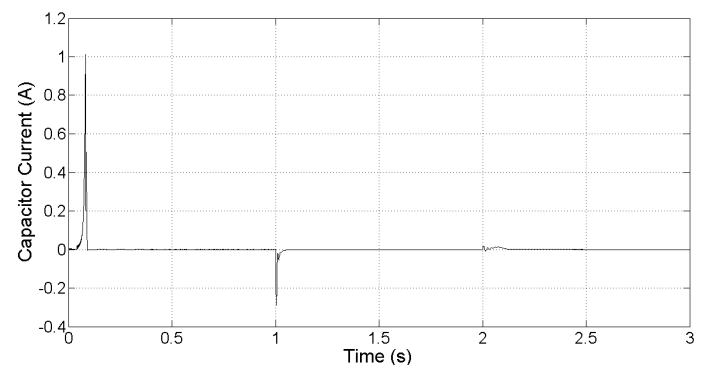

a)

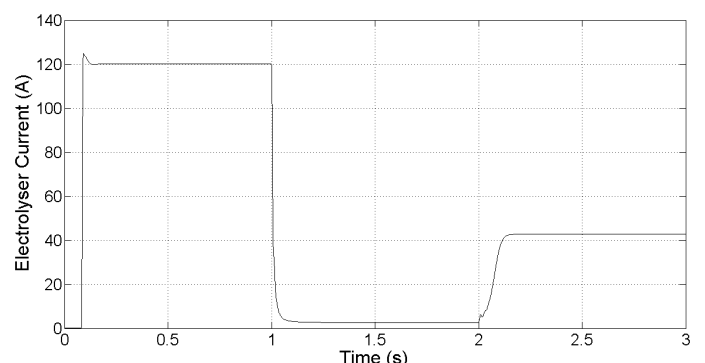

b)

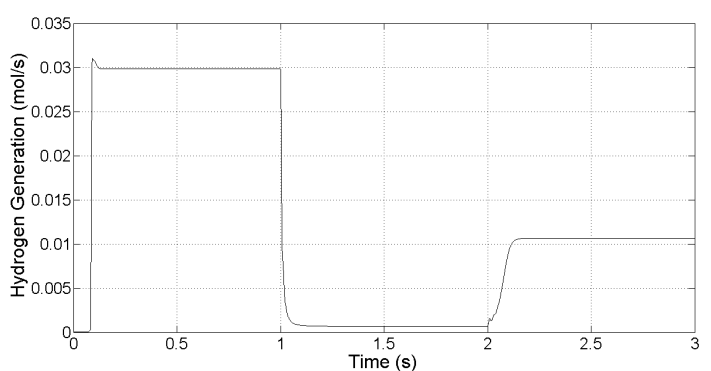

c)

Fig. 4. Change in load current flows and Hydrogen production when wind speed steps from $12 \mathrm{~m} / \mathrm{s}$ to $5 \mathrm{~m} / \mathrm{s}$ to $8 \mathrm{~m} / \mathrm{s}$.a)capacitor current, b) electrolyser current, c) hydrogen generation.

\section{B) Baglan Hydrogen Centre Production}

The hydrogen production rate at wind speeds from $3 \mathrm{~m} / \mathrm{s}$ to $12 \mathrm{~m} / \mathrm{s}$ is determined based on the model presented in section 2. This is used to calculate the monthly and overall hydrogen production yields for the Baglan Hydrogen Centre. This is presented in Table I below.

Table I. - Monthly wind speeds and potential hydrogen production at Baglan Hydrogen Centre

\begin{tabular}{|l|c|c|c|}
\hline MONTH & $\begin{array}{c}\text { AVERAGE } \\
\text { WIND } \\
\text { SPEED } \\
(\mathrm{m} / \mathrm{s})\end{array}$ & $\begin{array}{c}\text { AVERAGE } \\
\text { HYDROGEN } \\
\text { PRODUCTION } \\
(\mathrm{kg} / \mathrm{day})\end{array}$ & $\begin{array}{c}\text { TOTAL } \\
\text { HYDROGEN } \\
\text { PRODUCTION } \\
(\mathrm{kg})\end{array}$ \\
\hline January & 3.4 & 0.79 & 24.5 \\
\hline February & 2.9 & 0.53 & 15.0 \\
\hline March & 3.8 & 0.78 & 24.3 \\
\hline April & 3.0 & 0.59 & 17.6 \\
\hline May & 2.5 & 0.45 & 13.8 \\
\hline June & 3.0 & 0.54 & 16.2 \\
\hline July & 4.6 & 1.06 & 32.7 \\
\hline August & 3.7 & 0.75 & 23.2 \\
\hline September & 4.6 & 1.10 & 32.9 \\
\hline October & 4.3 & 1.05 & 32.5 \\
\hline November & 4.0 & 0.94 & 28.2 \\
\hline December & 1.8 & 0.27 & 8.34 \\
\hline Total & 3.48 & 0.74 & 269 \\
\hline
\end{tabular}

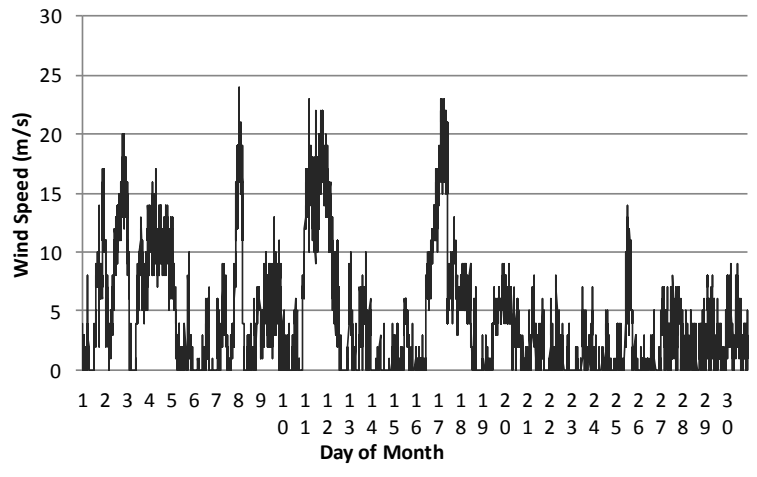

Fig. 5. Recorded Baglan wind speed for November 2010

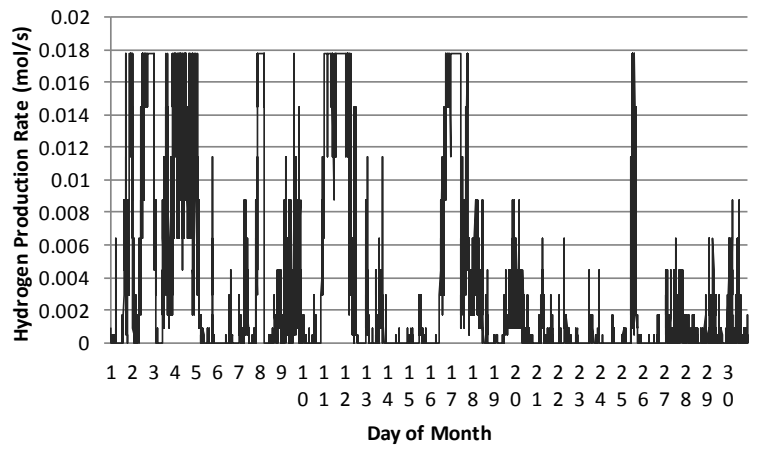

Fig. 6. Hydrogen production for November 2010

Figure 5 shows the variation in wind speed over one month, whilst Figure 6 shows the concurrent hydrogen production. In total, the proposed system would produce $269 \mathrm{~kg}$ of hydrogen in the year analysed. By month, the average daily hydrogen production shows a large range with a minimum of $0.27 \mathrm{~kg} /$ day produced in December, and a maximum of $1.10 \mathrm{~kg}$ /day produced in September. Even in December with a very low average wind speed regime of $1.8 \mathrm{~m} / \mathrm{s}$, a total of $8.34 \mathrm{~kg}$ of hydrogen can be produced.

\section{Discussion}

The electrolyser considered in this paper has the ability to operate at a very low power levels compared to its rated power. The electrolyser is based on a proton exchange membrane electrolyser. With some electrolyser technologies, such a low turn down rate may not be achievable, and other control strategies, such as combining the electrolyser with a battery must be considered [5].

The simulation in this paper considers the power electronic interfaces (full bridge ac/dc rectifier and $\mathrm{dc} / \mathrm{dc}$ buck converter) as simple average models, i.e. the $\mathrm{DC} / \mathrm{DC}$ converter is represented by the voltage ratio imposed by its duty cycle. In a real system, the inductive and capacitive components of the DC/DC buck converter should be considered as well as the switching frequency. This will affect the control of the system, as well as impose an additional variability on the current entering the electrolyser. This variability may be reduced by increasing the filtering on the output of the DC/DC 
converter. Variability of the electrolyser power input can result in reduced performance [2].

\section{Conclusions}

A stand-alone wind-hydrogen system based on a PEM electrolyser is developed and modelled using MATLAB/Simulink $^{\mathrm{TM}}$. A control strategy to extract the maximum power from the wind, and so ensure maximum hydrogen production, is included. The performance of the system under step changes in wind speed is assessed, in order to demonstrate the effectiveness of the MPPT, and the viability of the proposed system. The performance of the system in steady state is used to determine the hydrogen production rates for different wind speeds. These results are used to determine the potential yield from such a system located at the University of Glamorgan's Hydrogen Centre at Baglan Energy Park from recorded wind speed data. It is seen that the proposed system works well under varying wind speed, and the MPPT is capable of tracking the maximum power point. The system functions at start up, with all generated current entering the capacitor, until sufficient voltage has been achieved for the electrolyser to start producing hydrogen. Hydrogen can be produced throughout the year even in months with low average wind speeds.

\section{Acknowledgement}

This work was supported by the CymruH2Wales project, part of the Low Carbon Research Institute (LCRI) Convergence Programme. The CymruH2Wales project has been supported by the European Regional Development Fund (ERDF) through the (Llywodraeth Cymru) Welsh Government.

\section{References}

[1] M. Druga, C. Nichita, G. Barakat, and E. Ceanga, "Stand-Alone Wind Power System Operating with a Specific Storage Structure," presented at the International Conference on Renewable Energies and Power Quality, Valencia, Spain, 2009.

[2] S. G. Tesfahunegn, O. Ulleberg, P. J. S. Vie, and T. M. Undeland, "Optimal shifting of Photovoltaic and load fluctuations from fuel cell and electrolyzer to lead acid battery in a Photovoltaic/hydrogen standalone power system for improved performance and life time," Journal of Power Sources, vol. 196, pp. 10401-10414, Dec 2011.
[3] F. Valenciaga and P. Puleston, "Supervisor Control for a Stand-Alone Hybrid Generation System Using Wind and Photovoltaic Energy," IEEE Transactions on Energy Conversion, vol. 20, pp. 398-405, June 20052005.

[4] H. de Battista, R. J. Mantz, and F. Garelli, "Power conditioning for a wind-hydrogen energy system," Journal of Power Sources, vol. 155, pp. 478-486, Apr 2006.

[5] F. Valenciaga and C. A. Evangelista, "Control design for an autonomous wind based hydrogen production system," International Journal of Hydrogen Energy, vol. 35, pp. 5799-5807, Jun 2010.

[6] M. J. Khan and M. T. Iqbal, "Analysis of a small wind-hydrogen stand-alone hybrid energy system," Applied Energy, vol. 86, pp. 2429-2442, Nov 2009.

[7] M. Little, M. Thomson, and D. Infield, "Electrical integration of renewable energy into stand-alone power supplies incorporating hydrogen storage," International Journal of Hydrogen Energy, vol. 32, pp. 1582-1588, Jul-Aug 2007.

[8] O. C. Onar, M. Uzunoglu, and M. S. Alam, "Dynamic modeling, design and simulation of a wind/fuel cell/ultra-capacitor-based hybrid power generation system," Journal of Power Sources, vol. 161, pp. 707722, Oct 2006.

[9] S. M. Muyeen, R. Takahashi, and J. Tamura, "Electrolyzer switching strategy for hydrogen generation from variable speed wind generator," Electric Power Systems Research, vol. 81, pp. 11711179, May 2011.

[10] A. G. Dutton, J. A. M. Bleijs, H. Dienhart, M. Falchetta, W. Hug, D. Prischich, and A. J. Ruddell, "Experience in the design, sizing, economics, and implementation of autonomous wind-powered hydrogen production systems," International Journal of Hydrogen Energy, vol. 25, pp. 705-722, Aug 2000.

[11] M. E. Haque, M. Negnevitsky, and K. M. Muttaqi, "A Novel Control Strategy for a Variable-Speed Wind Turbine With a Permanent-Magnet Synchronous Generator," IEEE Transactions on Industry Applications, vol. 46, pp. 331-339, Jan-Feb 2010.

[12] C. N. Bhende, S. Mishra, and S. G. Malla, "Permanent Magnet Synchronous Generator-Based Standalone Wind Energy Supply System," Sustainable Energy, IEEE Transactions on, vol. 2, pp. 361-373, 2011.

[13] F. Valenciaga, P. F. Puleston, and P. E. Battaiotto, "Power control of a solar/wind generation system without wind measurement: A passivity/sliding mode approach," IEEE Transactions on Energy Conversion, vol. 18, pp. 501-507, Dec 2003.

[14] M. E. Haque, K. M. Muttaqi, M. Negnevitsky, and Ieee, Control of a Stand Alone Variable Speed Wind Turbine with a Permanent Magnet Synchronous Generator. New York: IEEE, 2008. 